\title{
1 Towards Type-Selective Carbon Nanotube \\ 2 Growth at Low Substrate Temperature via \\ 3 Chemical Vapour Deposition
}

4 Jeng-Shiung Chen, ${ }^{\dagger}$ Vlad Stolojan, ${ }^{\dagger}$ S. Ravi P. Silva ${ }^{\dagger^{* *}}$

$5 \uparrow$ †dvanced Technology Institute, University of Surrey, Guildford, Surrey, United

6 Kingdom, GU2 7XH

\section{ABSTRACT}

8 Carbon nanotubes have been intensively researched for electronic applications, driven

9 by their excellent electronic properties, with the goals being control and

10 reproducibility of growth, semiconducting/metallic type selectivity and maintaining

11 high quality of carbon nanotubes, in a process that is temperature-compatible with the

12 electronics. Photo-thermal chemical vapour deposition can achieve these goals and,

13 through a thorough investigation of the parameter space, we achieve very high

14 nanotube-quality and growth rates, and produce a phase-diagram that reveals distinct

15 regions for growing semiconducting and metallic single-walled nanotubes, as well as

16 multi-walled ones. Correlation with the carbon-catalyst phase diagram allows for the

17 development of a novel growth model. We propose that the temperature-gradient

18 induces carbon diffusivity-gradient across the catalyst to yield the high growth rate.

19 This is attributed to the increase of $\alpha$-iron of catalyst. The growth control

20 demonstrated here allows for integration of the nanotube growth process by

21 photo-thermal deposition into mainstream electronics manufacture. 


\section{1. Introduction}

2 Carbon nanotubes (CNT) have been utilised in a multitude of applications, due to 3 their outstanding electronic properties, such as for field effect transistors (FET), 4 interconnects, and solar cells [1-5]. More recently, they have been used in CMOS 5 circuits and memory devices [6,7]. For large scale adoption for applications, it is 6 increasingly important to control the specific electronic type, morphology and the 7 quality of the CNT during it growth.

8 However, by only examining the impact of one parameter, such as temperature $[8,9]$ 9 or reactant gas flow rate [10], it may omit the cross- or dependent-interactions 10 between parameters. Hence, a key objective of this study is to determine growth 11 windows for controlled and reproducible quality, growth rate, and electronic 12 properties while experimenting with the process temperature, reactant gas ratio, and 13 gas flow rate. In this work, we use a photo-thermal chemical vapour deposition 14 (PTCVD) which intensively heats the catalyst and meanwhile keeps the substrate at 15 lower temperature [11]. From the temperature gradient, a novel growth model 16 correlated with carbon-catalyst phase diagram is proposed, to account for the 17 variation in CNT growth rate.

18 In order to obtain a global understanding of the effect of the process parameters, we 19 firstly summarise the relationships between the CNT growth rate, process 20 temperature, and reactant gas ratio. Consequently, the relationships between the 21 quality and the electronic properties (semiconducting and metallic) of the nanotube 22 and the two key variables extracted are correlated with Raman spectroscopy 23 information.

\section{Experimental}

2.1 Process of growing CNT via PTCVD

27 The growth conditions for the fabrication of different types of CNT are studied via 28 the PTCVD, which irradiates the substrate from the top with IR lamps, uniformly 29 across the substrate surface at 2 Torr of gas mixture of acetylene and hydrogen, as 30 shown in Figure 1a. [12, 13]. 


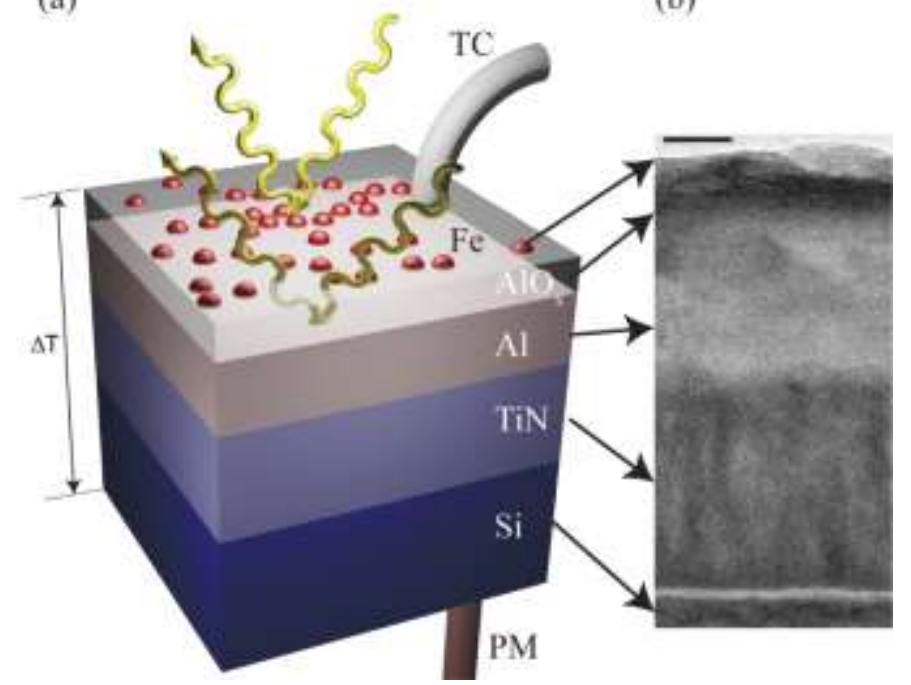

2 Figure 1. (a) The illustration of structure of substrate which is confirmed by 3 transmission electron microscopy (TEM) as shown in the right of panel (b). The $\Delta \mathrm{T}$ is 4 the temperature difference between catalyst and bottom substrate temperature. The 5 iron catalyst (red bead) is intensively heated by the IR lights. (The scale bar in (b) is $6 \quad 10 \mathrm{~nm})$

7 The process temperature is controlled by a digital thermal energy controller 8 (Eurotherm) to modify the percentage of total energy output of eight $1 \mathrm{~kW}$ IR lamps $9 \quad(100 \%$ power output ( $\mathrm{p} / \mathrm{o})$ corresponds to $8 \mathrm{~kW})$. A K-type thermocouple (TC) and a 10 pyrometer (PM) are simply attached to a dummy substrate for monitoring the surface 11 and bottom temperature of the substrates to inspect the catalyst $\left(\mathrm{T}_{\mathrm{C}}\right)$ and substrate 12 temperatures $\left(\mathrm{T}_{\mathrm{S}}\right)$, as shown in the Figure 1a. The tested power outputs ranged from 1330 to $70 \%$ with $10 \%$ intervals corresponds to the $\mathrm{T}_{\mathrm{C}}$ from $\sim 570$ to $880{ }^{\circ} \mathrm{C}$ and the $\mathrm{T}_{\mathrm{S}}$ 14 from 321 to $515^{\circ} \mathrm{C}$ at the top and bottom of the substrates, respectively.

15 For reduction and CNT growth, acetylene and hydrogen are chosen as the reactant 16 gases and are pre-mixed in the manifold prior to introduction into the reactor. The 17 growth process is divided into two steps that are the reduction of the catalyst from 18 oxidised film to metallic islands and the CNT growth. During the reduction step, 100 19 sccm hydrogen is flowed at $\mathrm{T}_{\mathrm{C}}=600{ }^{\circ} \mathrm{C}\left(\mathrm{T}_{\mathrm{S}} \sim 330^{\circ} \mathrm{C}\right)$ for $5 \mathrm{mins}$ and subsequently, the 20 acetylene is introduced for another 10 mins for CNT growth. Furthermore, our 21 previous work has proved that the uniformity of catalyst can be improved after the 22 reduction [13] and it suggests the narrow distribution of the diameter of CNTs.

23 We used a range of reactant gas ratios of acetylene to hydrogen $\left(\mathrm{Q}_{\mathrm{A} / \mathrm{H}}\right)$, from 2 to 20 $24 \%$ with $2 \%$ steps, in order to study the effect of the ratio of carbon to hydrogen on the 
1 growth rate. Besides the gas ratio variation, we also tested the total flow rate effect by

2 doubling the total flow rate with the same acetylene ratio, whilst keeping the chamber

3 pressure constant (2 Torr); this again would increase the reaction rate, as seen later in

4 this paper. The two tested total flow rates are maintained at 100 and $200 \mathrm{sccm}$, which

5 are termed as the lower (LFR) and higher flow rate (HFR). It gives a handle on the

6 limiting factors when it comes to increasing the growth rates, as well as the pressure

7 conditions in the catalyst environs. For instance, $2 \% \mathrm{Q}_{\mathrm{A} / \mathrm{H}}$ of LFR means we used 2

$8 \mathrm{sccm}$ acetylene and $98 \mathrm{sccm}$ hydrogen and for the HFR, the flow rates become $4 \mathrm{sccm}$

9 acetylene and $196 \mathrm{sccm}$ hydrogen to maintain the $\mathrm{Q}_{\mathrm{A} / \mathrm{H}}=2 \%$.

\subsection{Structure of substrate}

12 The substrate for CNT growth, as illustrated in Figure 1a, is composed of $30 \mathrm{~nm}$ of 13 titanium nitride (TiN) as a thermal barrier layer [12] and $25 \mathrm{~nm}$ of aluminium with 5 $14 \mathrm{~nm}$ of native alumina as an anchor layer to avoid the catalyst from coalescence [14]. 15 The catalyst, $5 \mathrm{~nm}$ of iron, is subsequently coated on the anchor layer. These were 16 deposited by sputtering onto a pre-cleaned $\mathrm{Si}$ and the thickness of the substrate 17 structure is confirmed by transmission electron microscopy (TEM), as shown in 18 Figure 1b. As the IR light irradiates the catalyst, the iron layer efficiently gains heat energy to reduce the iron oxide and growing of CNT. Moreover, some of the IR light does not hit the catalyst but penetrate through the alumina and is reflected back toward the catalyst by the aluminium, owing to the high IR transparency and reflectivity for alumina and aluminium, respectively $[15,16]$. Hence, the energy is coupled directly to the growth front on the top of the catalyst, and efficiently uses the energy for growth rather than dissipating it for silicidation or heating of the chamber, as in the case of hot-wall CVD.

The bottom layer, TiN, mainly protects the upper layers from forming silicide and retard the loss of heat energy, to keep the $\mathrm{Si}$ at a lower temperature. It can also act as a further reflector for long wavelength IR radiation. Hence, there is a significant temperature difference $(\Delta \mathrm{T})$ between the catalyst and the substrate $\mathrm{Si}$, which is confirmed by the TC and PM meter readings. The optical heating is the key to induce such a high temperature difference and the iron absorbs most energy for reduction to iron oxide and catalysing the CNT growth. 


\subsection{Material characterisation}

The as-grown CNTs are then analysed by scanning electron microscopy (SEM) (FEI Quanta 200) to measure the lengths of CNTs, and for calculating the growth rates. It is assumed that CNTs grow from the time acetylene is turned on to when it is turned off. The Raman spectra are recorded at two excitation energies, which are 2.41 and $1.58 \mathrm{eV}$, in backscattering geometry, using $50 \times$ objective lens with $5 \mu \mathrm{m}$ spot size (Renishaw). The scanned range is from 50 to $4000 \mathrm{~cm}^{-1}$ to include all the first and second order resonance Raman features. The power densities of lasers are kept as low as $\sim 9 \mu \mathrm{W} / \mu \mathrm{m}^{2}$ to avoid the heating-induced shift of the peaks, excessive heating and damaging of the samples [17]. During the Raman measurement, we also record the Si signal for in-spectrum calibration of the Raman peak positions [17]. The measured RBM, G-, 2D-, and D-band are fitted by Lorentzian function to analyse the peak position, intensity, and peak intensity for further investigations.

\section{Growth Model}

\subsection{Proposed growth model}

A novel CNT growth model associated with high temperature gradient across the substrate is established. Based on the optical top-down heating framework of the PTCVD, the top surface of catalyst can be sufficiently heated to dissociate the acetylene into carbon atoms. Consequently, the hotter surface of the catalyst with temperature $T_{R}$, leads the carbon atoms to migrate with higher diffusivity $\left(D_{R}\right)$ to the bottom of catalyst with temperature $T_{R}$, due to the induced high temperature gradient within it, as depicted in Figure 2 [18-20]. The temperature recorded at the bottom of the substrate $\left(\mathrm{T}_{\mathrm{S}}\right)$ is $\sim 250{ }^{\circ} \mathrm{C}$ lower, indicating an overall temperature gradient $\left(\Delta \mathrm{T}=\mathrm{T}_{\mathrm{C}}-\mathrm{T}_{\mathrm{S}}\right)$ throughout the structure. 


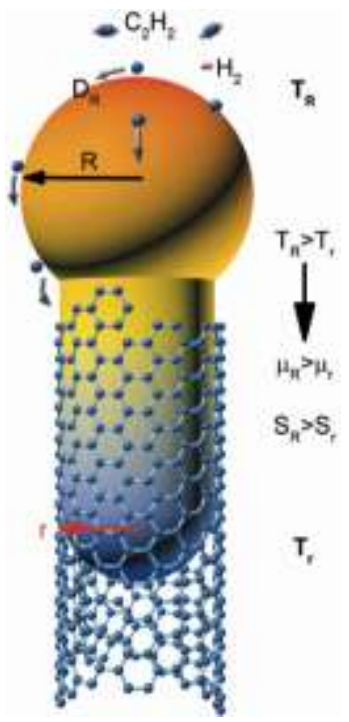

2 Figure 2. The illustration of heated catalyst exhibit plastic deformation. The bigger

3 radius $(R)$ and higher temperature $\left(T_{R}\right)$, carbon solubility $\left(S_{R}\right)$, diffusivity $\left(D_{R}\right)$, and

4 chemical potential $\left(\mu_{R}\right)$ are found at the top of the catalyst to enhance the growth rate.

53.2 Plastic deformation of the catalyst

6 In SEM observations (see Figure 3), we find the CNT growth occurs via the 7 tip-growth mechanism and plastic deformations of the catalyst encapsulated in tubes 8 are observed [21-23]. The catalyst is embedded in the top of CNT which are grown at $9 \mathrm{~T}_{\mathrm{C}}=774{ }^{\circ} \mathrm{C}, \mathrm{Q}_{\mathrm{A} / \mathrm{H}}=16 \%$ of the LFR. It can be observed that the black particles which are only found in the top of CNT that suggests the tip-growth mechanism. It has been

11 reported that alumina-supported catalyst allows either the tip-[24] or based growth

12 [25] mechanism. We believe that the tip-growth mechanism in this study is induced 13 by the top-down heating scheme.

14 Some catalyst particles exhibit the plastic deformations as pointed by the red 15 arrows and the green arrows point the catalyst with spherical shape. The plastic 16 deformation of catalyst implies that the catalyst experiences the reshaping during 17 growth. This observation is consistent with the Moseler et al.'s work which proves the 18 driven force induced by the curvature difference between the two ends of catalyst to 19 assist the surface diffusion of carbon on catalyst [23]. Moreover, in their work, as the 20 growth process is finished, the catalyst particles turn to sphere shapes which is 21 consistent to the catalyst pointed by the green arrows. In addition, the curvature 22 difference between the top and bottom surface of catalyst will lead to an axial driving 23 force induced by the gradient of the chemical potential $(\mu)$ [23]. 


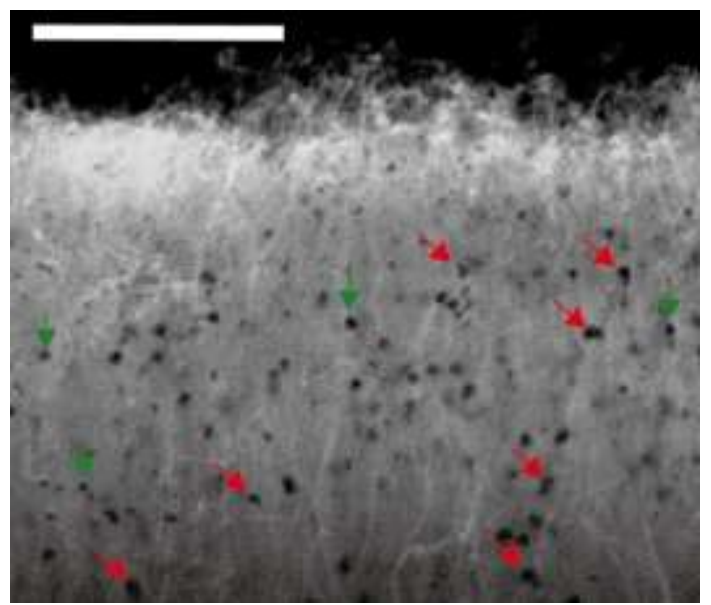

3 Figure 3. SEM image of plastic deformation of catalyst in CNT. The SEM image of

4 the top of as-grown $\mathrm{CNT}$ fabricated by $\mathrm{T}_{\mathrm{C}}=774{ }^{\circ} \mathrm{C}(50 \% \mathrm{p} / \mathrm{o}), \mathrm{Q}_{\mathrm{A} / \mathrm{H}}=16 \%$, and LFR.

5 The red arrows point the plastic deformation of catalyst and the green arrows point

6 the round shape catalyst. The catalyst size observed here is generally smaller than 20

$7 \mathrm{~nm}$. The scale bar is $500 \mathrm{~nm}$.

8 The solubility of carbon in iron $\left(\mathrm{S}_{\mathrm{R}}\right)$ is also higher at the top surface, resulting in a

9 high carbon concentration gradient [26]. It should be mentioned that Klinke et al.

10 reported the concentration gradient is the main driving force for CNT growth rather

11 than temperature [27]. In their calculations, they only considered the exothermic

12 energy from acetylene dissociation. Thus, the catalyst is heated in random directions.

13 In our case, the heating direction is from the top surface of the catalyst. What is more, 14 the Gibbs energy of the reaction of carbon and iron is temperature-dependent, 15 decreasing with increasing temperature [28]. Hence, the intensively heated catalyst 16 surface is beneficial for enhancing the carbon solubility and thus, the growth rate and 17 quality can be enhanced. Note also that, once growth starts, the base substrate 18 temperature remains constant, even though CNTs absorb IR. This is due to the unique 19 design of the top-heating and the high process pressure used.

\section{Results and discussions}

\section{1 $\Delta T$ vs. CNT quality and growth rates}

22 The $\Delta \mathrm{T}$ correlated with the intensity of $\mathrm{D}$ - to G-band $\left(\mathrm{I}_{\mathrm{D}} / \mathrm{I}_{\mathrm{G}}\right)$ and the growth rates 23 are shown in Figure 4. It can be seen that the higher $\Delta \mathrm{T}$ enhances the CNT quality 
1 significantly, as shown in Figure 4a-d, which implies the catalyst stays at high 2 temperature to allow the carbon atoms migrating with high diffusivity to form 3 continuously into a hexagonal structure. Interestingly, the growth rates are maximised 4 at $\Delta \mathrm{T} \approx 300{ }^{\circ} \mathrm{C}$ (see Fig. $4 \mathrm{e}$ and $\mathrm{f}$ ). The higher $\Delta \mathrm{T}$ implies that the top surface is at 5 higher temperature and the phase of the catalyst will be changed, which is further 6 discussed.

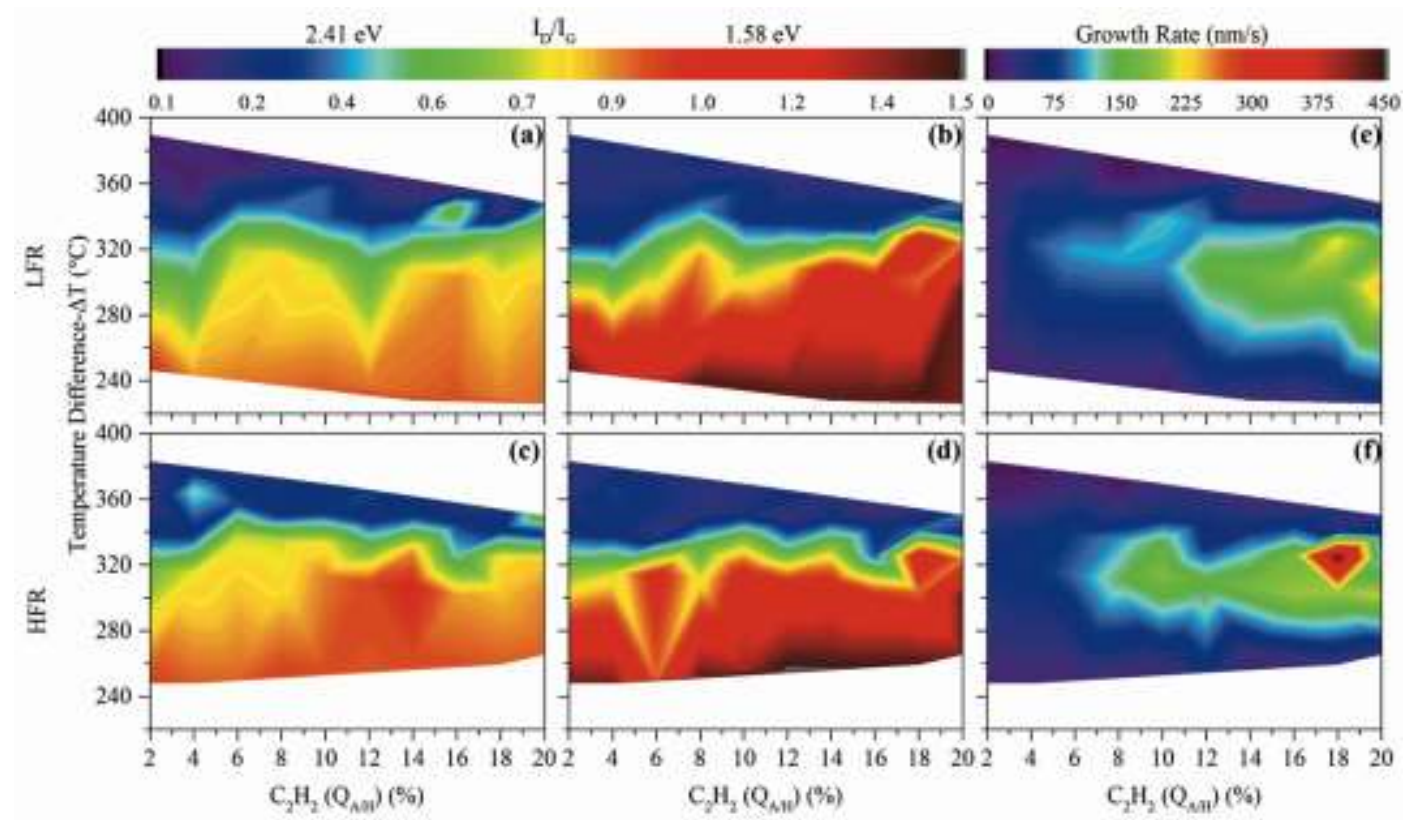

9 Figure 4. The relationships of CNT quality $\left(\mathrm{I}_{\mathrm{D}} / \mathrm{I}_{\mathrm{G}}\right)$ (a)-(d) and growth rate (e)-(f) 10 between the $\Delta \mathrm{T}$ and acetylene ratio. The L/HFR means the lower/higher flow rate and 11 HFR is double of LFR. The 2.41 and 1.58 note the $\mathrm{I}_{\mathrm{D}} / \mathrm{I}_{\mathrm{G}}$ are measured by excitation 12 energies of 2.41 and $1.58 \mathrm{eV}$.

\subsection{Growth rates}

The growth rates at the LFR $\left(\mu_{\mathrm{LFR}}\right)$ and at the HFR $\left(\mu_{\mathrm{HFR}}\right)$ exhibit a similar trend, as depicted in Figure 5a,b. As more carbon is supplied, the growth rate increases up to a maximum, for a relatively narrow operational window which is at $\mathrm{HFR}, \mathrm{Q}_{\mathrm{A} / \mathrm{H}}=18 \%$, and $\mathrm{T}_{\mathrm{C}}=772{ }^{\circ} \mathrm{C}\left(\mathrm{T}_{\mathrm{S}}=447{ }^{\circ} \mathrm{C}\right)$, to give the peak growth rate of $442 \mathrm{~nm} / \mathrm{s}$. Compared with the CNT growth with temperature gradient generated by ohmic heater [29], our

19 best growth rate, $442 \mathrm{~nm} / \mathrm{s}$, is 66 times higher. The lowest catalyst temperature at 20 which SWCNT are obtained here is $\mathrm{T}_{\mathrm{C}} \sim 560{ }^{\circ} \mathrm{C}\left(\mathrm{T}_{\mathrm{S}}=320{ }^{\circ} \mathrm{C}\right)$, at $\mathrm{Q}_{\mathrm{A} / \mathrm{H}}=6 \%$ in the $\mathrm{LFR}$ 21 to give the growth rate of $\sim 18 \mathrm{~nm} / \mathrm{s}$ (the bottom of the substrate is generally $\sim 200-400$ $22{ }^{\circ} \mathrm{C}$ cooler, depending on the heat transfer sub-layer design). To the best of our 
1 knowledge, the lowest temperature for SWCNT growth is $350{ }^{\circ} \mathrm{C}$ with growth rate of $2 \sim 3 \mathrm{~nm} / \mathrm{s}$ by plasma-enhanced CVD (PECVD) [28]. Compared with ref. [30], our 3 growth rate is 6 times higher at a lower temperature and our effective growth area can 4 be up to 4" in diameter. Furthermore, it should be noted that in our PTCVD process, no oxygen-containing precursor and plasma are applied for enhancing the growth rate and lowering the temperature at the growth front. The highest growth rates reported for PECVD usually range from 48 to $176 \mathrm{~nm} / \mathrm{s}$, which are significantly lower than the PTCVD [31-35]. Although the phenomenal "super" growth rates achieved by the catalytic CVD range from 1600 to $4167 \mathrm{~nm} / \mathrm{s}$, the process temperature is relatively higher $\left(850^{\circ} \mathrm{C}\right)$ or water vapour is applied as a source "gas" in the growth regime, which has a detrimental effect on the quality of the CNTs and their subsequent integration with semiconductor fabrication processes [10, 36, 37].
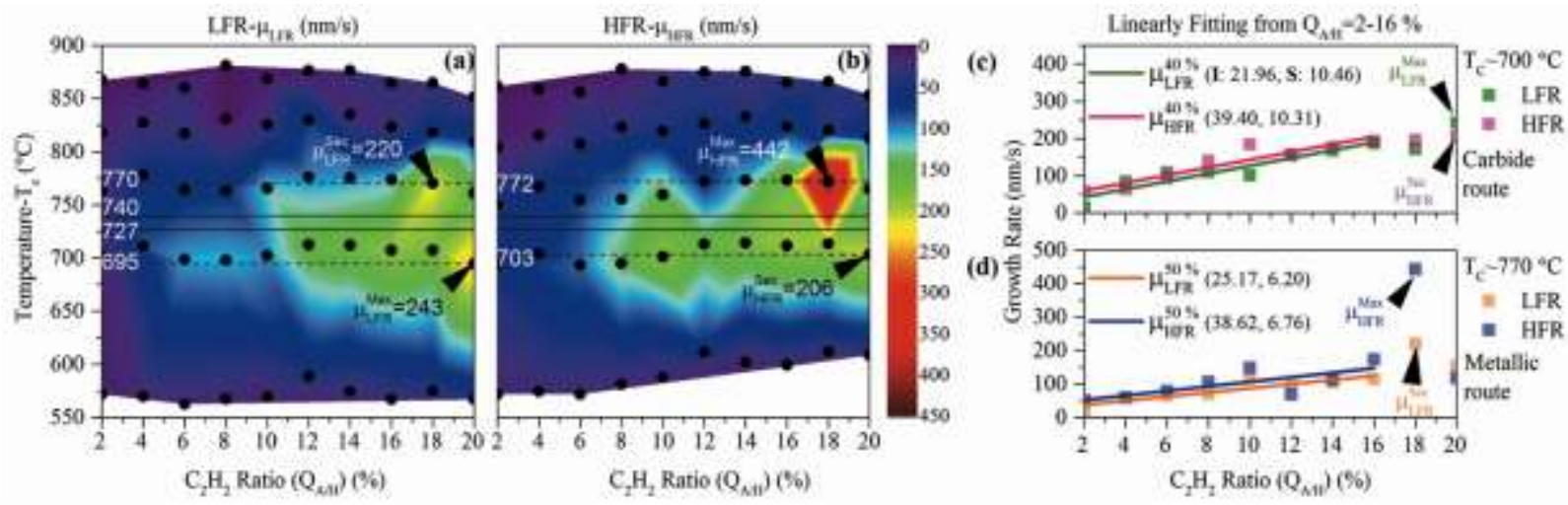

Figure 5. The relationships of the CNT growth rates between the catalyst temperature $\left(\mathrm{T}_{\mathrm{C}}\right)$ and the acetylene ratio for LFR and HFR. (a)-(b) The CNT growth rates obtained from the LFR and the HFR are plotted against the catalyst temperature and acetylene ratio. The black arrows indicate the top two growth rates and the solid and dashed lines point out the eutectoid temperatures of $\alpha / \gamma-\mathrm{Fe}$ and $\alpha / \mathrm{Fe}_{3} \mathrm{C}$, respectively and catalyst temperatures. (c)-(d) The growth rates of the CNT grown at $T_{C} \sim 700$ and 770 ${ }^{\circ} \mathrm{C}$ (corresponds to the lower and upper dashed lines in a and $\mathrm{b}$ ) are plotted against the acetylene ratio and the solid lines are the linear fitting from $\mathrm{Q}_{\mathrm{A} / \mathrm{H}}=2-16 \%$. The I and $\mathrm{S}$ means the intercept and slope of the linear equation and the black dots are the data points.

The current understanding of the growth rate proposed by Klinke et al.'s calculated results is that it increases exponentially with increasing temperature from 500 to 750 ${ }^{\circ} \mathrm{C}$ which is inconsistent with our result [27]. This inconsistency probably arose as a result of the phase change not being considered in their calculations. Nevertheless, 
1 more recently, Wirth et al. proposed two growth routes that are decided by the eutectoid points of $\gamma / \alpha-\mathrm{Fe}$ and $\alpha-\mathrm{Fe} / \mathrm{Fe}_{3} \mathrm{C}$ which are of $740{ }^{\circ} \mathrm{C}$ and $727{ }^{\circ} \mathrm{C}$ [38]. They have shown that bulk phase diagram matches very well their experimental XRD data observed during growth of CNTs. Hence, for growth temperatures above $\mathrm{T}_{\mathrm{C}}=740^{\circ} \mathrm{C}$, the growth rate follows the metallic $(\gamma / \alpha-\mathrm{Fe})$, whilst below $727{ }^{\circ} \mathrm{C}$, it follows a carbide $\left(\alpha-\mathrm{Fe} / \mathrm{Fe}_{3} \mathrm{C}\right)$ route.

To understand the effect of temperature on growth rates in the L/HFR, what we propose is that the carbon diffusivity of different phases of catalyst dominates the growth rate. In the metallic route (above $740{ }^{\circ} \mathrm{C}$ ), the catalyst is a mix of $\gamma$ - and $\alpha-\mathrm{Fe}$, and the growth rate is governed by the $\alpha$-Fe because of higher diffusion coefficient of two to one orders of magnitude from $\mathrm{T}_{\mathrm{C}}=740$ to $860{ }^{\circ} \mathrm{C}$ than $\gamma$-Fe [20]. Thus, we conclude that in the metallic route, the increasing growth rate with decreasing temperature is attributed to the increasing $\alpha$-Fe in the catalyst, thus agreeing with the Fe-C phase diagram. Our results agree with Kimura et al. [39], who found that the maximum growth rate occurs at $750{ }^{\circ} \mathrm{C}$ and decreases with increasing temperature.

In the carbide route (below $727^{\circ} \mathrm{C}$ ), because of the smaller carbon diffusivity of cementite $\left(\mathrm{Fe}_{3} \mathrm{C}\right)$ than either $\gamma$ - or $\alpha-\mathrm{Fe}$ [20], the growth rates are mainly restricted by the percentage of the carbide phase within the catalyst. In our tested temperature range for the carbide route, from $\mathrm{T}_{\mathrm{C}}=700$ to $570{ }^{\circ} \mathrm{C}$, the diffusion coefficients of cementite are lower than the diffusion coefficients of $\alpha$-Fe by one to four orders of magnitude, respectively [20]. As the temperature decreases, the amount of $\alpha$-Fe decreases (according to the $\mathrm{Fe}-\mathrm{C}$ phase diagram), which means that the growth route is cementite and the growth rate decreases accordingly. Therefore the growth rates for the respective routes are restricted mainly by $\gamma$-Fe and the carbide in metallic and carbide routes and our model agrees both with experimental results and the $\mathrm{Fe}-\mathrm{C}$ phase diagram. With regards to the acetylene ratio $\left(\mathrm{Q}_{\mathrm{A} / \mathrm{H}}\right)$, the growth rates are merely maximised at the $\mathrm{Q}_{\mathrm{A} / \mathrm{H}}=20 \%$ at $\mathrm{T}_{\mathrm{C}} \sim 700{ }^{\circ} \mathrm{C}$ and $18 \%$ at $\mathrm{T}_{\mathrm{C}} \sim 770{ }^{\circ} \mathrm{C}$ in the LFR and the HFR, respectively and the corresponding cross sectional SEM images are shown in Fig. 6. 

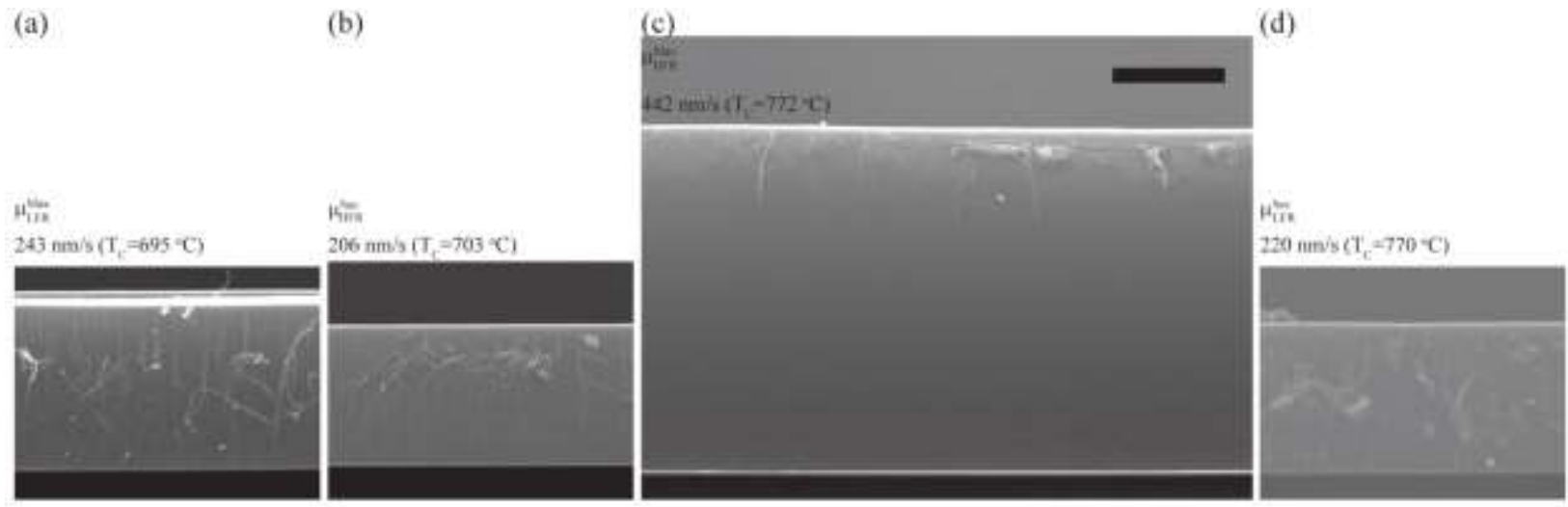

Metallic Route

2 Figure 6. The cross-sectional SEM images of top two growth rates in metallic and

3 carbide route. (a)-(b) The cross-sectional SEM images of the CNT grown at $\mathrm{T}_{\mathrm{C}} \sim 700$

$4{ }^{\circ} \mathrm{C}$ and $\mathrm{Q}_{\mathrm{A} / \mathrm{H}}=20 \%$ in the carbide route of the LHR and the HFR, respectively. The

5 corresponding growth rates labelled on panel (a) and (b) are the top two growth rates

6 in the carbide route. As gas flow rate is doubled (changed from the LFR to HFR), the growth rate slightly decreases from 243 to $206 \mathrm{~nm} / \mathrm{s}$. (c)-(d) The cross-sectional SEM images of the $\mathrm{CNT}$ grown at $\mathrm{T}_{\mathrm{C}} \sim 770{ }^{\circ} \mathrm{C}$ and $\mathrm{Q}_{\mathrm{A} / \mathrm{H}}=18 \%$ of the HFR and the LFR, respectively. The top two growth rates in the metallic route are 442 and $220 \mathrm{~nm} / \mathrm{s}$ for the LFR and the HFR, respectively. The scale bar in the panel $\mathrm{c}$ is $100 \mu \mathrm{m}$ and (a)-(d) share the same scale bar.

In order to assess the influence from the acetylene ratio, we chose the temperature at $\mathrm{T}_{\mathrm{C}} \sim 700{ }^{\circ} \mathrm{C}$ (carbide route) and at $\mathrm{T}_{\mathrm{C}} \sim 770{ }^{\circ} \mathrm{C}$ (metallic route) and displayed the growth rate as a function of the acetylene ratio, in Figure $5 \mathrm{c}$ and $\mathrm{d}$. The growth rates obtained at $\mathrm{T}_{\mathrm{C}} \sim 770{ }^{\circ} \mathrm{C}$ peaked at $\mathrm{Q}_{\mathrm{A} / \mathrm{H}}=18 \%$, but dropped rapidly at $20 \%$, suggesting that the catalyst has been poisoned by excessive carbon arrival [8]. In contrast, at $\mathrm{T}_{\mathrm{C}} \sim 700{ }^{\circ} \mathrm{C}$, we do not observe any significant drop in the growth rate. Instead, the growth rate increases gradually to peak at gas ratio of $20 \%$, and it shows that the catalyst is still active.

The catalyst activity of metallic and carbide routes is evaluated by linearly fitting the growth rates obtained from $\mathrm{T}_{\mathrm{C}} \sim 700{ }^{\circ} \mathrm{C}$ and $\sim 770{ }^{\circ} \mathrm{C}$, lowering gas ratios of 2 to 16 $\%$, before the poisoning of the catalyst. The positive slopes of the four solid lines in

23 Figure $5 \mathrm{c}, \mathrm{d}$ show that the activity of catalysts can be enhanced with increasing acetylene partial pressure. In other words, the impingement rate of carbon on the catalyst surface, $J_{c}$, is increased with increasing partial pressure of acetylene [27], 
1 while, the carbon solubility is also consequently increased to lead to the higher carbon

2 concentration gradient in the catalyst. Subsequently, the growth rate is enhanced.

3 Moreover, the catalyst in carbide route has higher activity than in the metallic route.

4 However, the sudden drop of growth rate in metallic route at $\mathrm{Q}_{\mathrm{A} / \mathrm{H}}=20 \% \mathrm{implies}$ that

5 the catalyst is poisoned. Instead, the carbide route retains the catalyst activity without

6 a significant drop of the growth rate.

\subsection{Raman spectroscopy}

9 The quality of as-grown CNT is analysed by Raman spectroscopy. A typical Raman 10 spectrum showing the constituent components and their impact on the physical 11 properties of the CNT is highlighted in Figure 7. Figure 7a illustrates a Raman spectra 12 of metallic SWCNT-rich sample grown at $\mathrm{T}_{\mathrm{C}}=876^{\circ} \mathrm{C}$ with $\mathrm{Q}_{\mathrm{A} / \mathrm{H}}=14 \%$ of LFR. There 13 are first order single resonance Raman scattering events, and will not disperse with $14 \mathrm{E}_{\text {Laser }}$. Figure $7 \mathrm{~b}$ and $\mathrm{c}$ are the RBM signals measured by $\mathrm{E}_{\text {Laser }}=1.58$ and $2.41 \mathrm{eV}$, 15 respectively. The $\mathrm{E}_{\text {Laser }}=1.58 \mathrm{eV}$ only probes the s-SWCNT and the $\mathrm{E}_{\text {Laser }}=2.41 \mathrm{eV}$ 16 can measure the RBM peaks from both s-SWCNT (150-210 $\left.\mathrm{cm}^{-1}\right)$ and $\mathrm{m}-\mathrm{SWCNT}$ $17\left(210-280 \mathrm{~cm}^{-1}\right)$ [40-42]. The Kataura plot applies to a narrow range of SWCNTs 18 diameters, 0.89 to $1.65 \mathrm{~nm}$; wider tubes are not detectable [40]. However, our narrow 19 catalyst size distribution suggests that the nanotube diameter distribution is also 20 narrow [13], and we are likely to be measuring the majority of the nanotubes. The 21 measured RBM signals are fitted with Lorentz functions to measure intensities and 22 positions, for quantitative analysis. The RBM frequencies are measured for the 23 as-grown CNT forests and thus arise from different types of CNTs, such as 24 semiconducting and metallic SWCNT. Hence, a quantitative study is carried out by 25 comparing the peak intensities of the measured RBM resonances. The $\mathrm{I}_{\mathrm{G}}$ of each 26 spectrum is normalised to 1 in order to consistently compare between samples. Then, 27 the RBM intensities can be summed to represent the production yield, depending on temperature and acetylene ratio. From this comparison, the optimised growth conditions are correlated with the temperature and reactant gas ratios for preferentially synthesising s/m-SWCNT. 

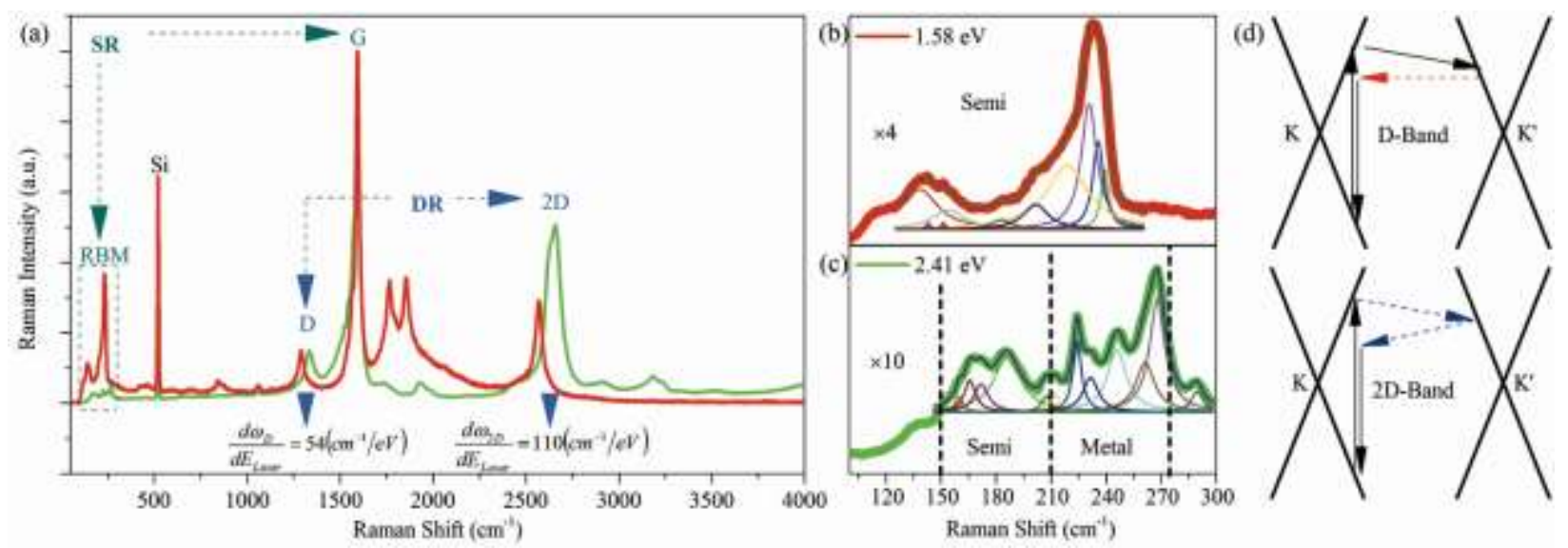

2 Figure 7. Raman spectra of as-grown SWCNT measured by $\mathrm{E}_{\text {Laser }}=1.58$ and $2.41 \mathrm{eV}$.

3 (a) Raman spectra of the CNTs grown at $\mathrm{T}_{\mathrm{C}}=876{ }^{\circ} \mathrm{C}$ with $\mathrm{Q}_{\mathrm{A} / \mathrm{H}}=14 \%$ of $\mathrm{LFR}$ 4 measured by $\mathrm{E}_{\text {Laser }}=1.58$ and $2.41 \mathrm{eV}$. The SR and DR stand for single- and 5 double-resonance Raman scatterings. The RBM $\left(100 \sim 500 \mathrm{~cm}^{-1}\right)$ and G-band $(\sim 1600$ $6 \mathrm{~cm}^{-1}$ ) are the SR, which will not disperse with changing laser energy. The D- and 7 2D-band are the DR and their dispersion with laser energy are 54 and $106 \mathrm{~cm}^{-1} / \mathrm{eV}$. 8 (b)-(c), The enlarged RBM from a are measured by $E_{\text {Laser }}=1.58$ and $2.41 \mathrm{eV}$, 9 respectively. In (b), the $\mathrm{E}_{\text {Laser }}=1.58 \mathrm{eV}$ only detects the semiconducting SWCNT and in $(\mathrm{c})$, the $\mathrm{E}_{\text {Laser }}=2.41 \mathrm{eV}$ can measure both semiconducting $\left(150 \sim 210 \mathrm{~cm}^{-1}\right)$ and metallic $\left(210 \sim 280 \mathrm{~cm}^{-1}\right)$ SWCNT. The colour curves under the RBM are fitted by Lorentz function. (d) The illustrations of Raman scattering process of D- and 2D-band. The D-band Raman scattering involves one-phonon inelastic scattering (black solid arrow) and defect elastic scattering (red dashed arrow). The 2D-band Raman scattering has two-phonon scattering presented in blue dashed arrows. (Redrawn after Dresselhaus et al. [43])

\subsubsection{CNT quality}

The D- and 2D-band are second order double resonances involving one-phonon and two-phonon Raman scattering, respectively, as shown in of Figure 7d (redrawn after Dresselhaus et al. [43]), which have a dispersion relationship with laser energy. The dispersion of D- and 2D-band in our measurement are 54 and $110 \mathrm{~cm}^{-1} / \mathrm{eV}$, which are close to dispersion values of SWCNT being reported before, 53 and $106 \mathrm{~cm}^{-1} / \mathrm{eV}$, respectively [43, 44]. Usually, the defect-induced D-band is used to evaluate the quality of carbon-based materials by comparing its intensity with the G-band. The 2D-band is also an indicator of higher order of carbon nanotubes [45]. In general, the 
1 turbostratic stacking will decrease the intensity of the 2D-band. Moreover, its

2 intensity is enhanced significantly as compared with multi-layer grapheme [46]. Thus,

3 the intensity of 2D-band can be a reference to compare with the $\mathrm{I}_{\mathrm{D}}$.

4 The intensity ratios of $\mathrm{D}$ - to $\mathrm{G}$-band $\left(\mathrm{I}_{\mathrm{D}} / \mathrm{I}_{\mathrm{G}}\right)$ are correlated to the catalyst 5 temperature and the acetylene ratio. By looking at the Raman data relating to the 6 quality of the carbon nanotubes $\left(\mathrm{I}_{\mathrm{D}} / \mathrm{I}_{\mathrm{G}}\right)$ in Figure 8 , we conclude the quality of the 7 CNT is improved primarily with increase in the process temperature, and secondarily 8 by a decrease in the acetylene ratio. This confirms the importance of the unique 9 PTCVD approach in engineering a solution for providing the highest possible process 10 temperature, whilst still maintaining the substrate at a much lower temperature.

11 Two excitation energies, $\mathrm{E}_{\text {Laser }}=2.41$ and $1.58 \mathrm{eV}$, are used for Raman spectroscopy 12 and the intensity ratios are labelled for the corresponding excitation energies as $13 I_{D} / I_{G}^{L F R / H F R}$ or the L/HFR, respectively. It should be noted that the as-grown 14 SWCNTs are expected to contain a mixture of both $\mathrm{m}-$ and s-SWCNT and the $15 \mathrm{E}_{\text {Laser }}=2.41 \mathrm{eV}$ plays a role in quantitatively identifying the ratio of s-SWCNT to 16 m-SWCNT [42].

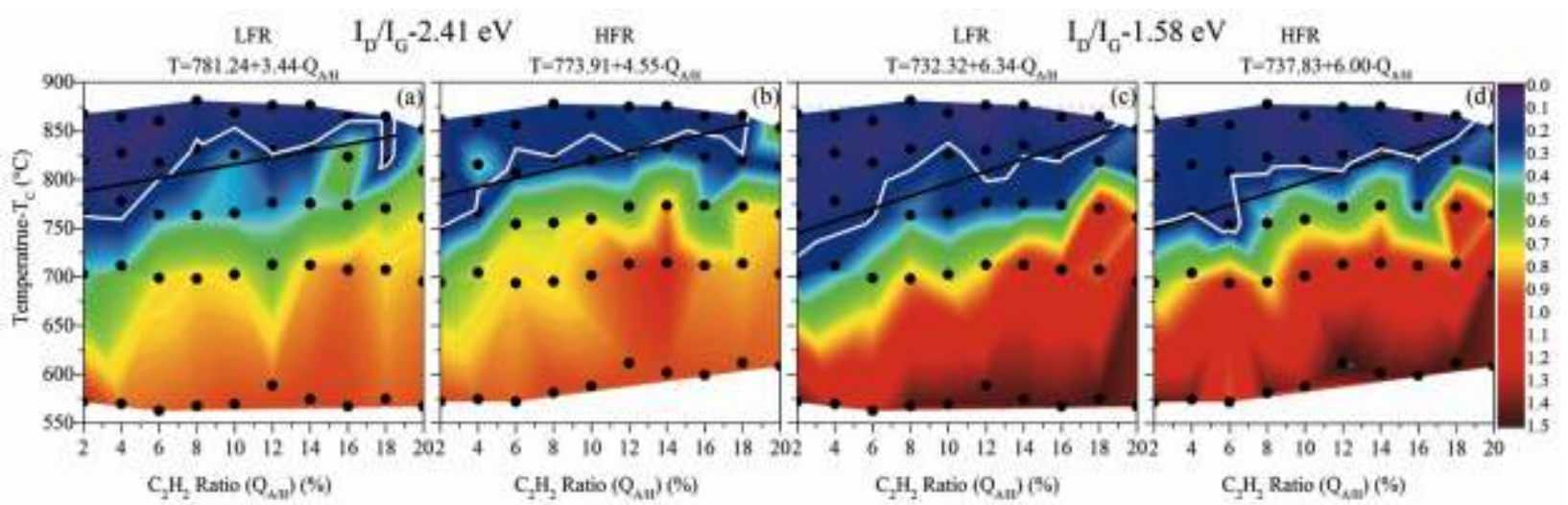

19 Figure 8 . The distributions of $\mathrm{I}_{\mathrm{D}} / \mathrm{I}_{\mathrm{G}}$ between the catalyst temperature and acetylene 20 ratio. (a)-(d) The $\mathrm{I}_{\mathrm{D}} / \mathrm{I}_{\mathrm{G}}$ of the LFR and the HFR measured by the $\mathrm{E}_{\text {Laser }}=2.41$ and 1.58 $21 \mathrm{eV}$ are correlated with the $\mathrm{T}_{\mathrm{C}}$ and $\mathrm{Q}_{\mathrm{A} / \mathrm{H}}$ and the black lines are the linear fittings of the 22 white lines which are the boundaries of $\mathrm{I}_{\mathrm{D}} / \mathrm{I}_{\mathrm{G}}=0.2$. The linear equations of the black 23 lines are labelled on each panel and the black dots are the data points. The positive 24 slopes of four linear equations imply the quality of CNT is degraded by increasing the 25 acetylene ratio and the intercepts are the minimum temperature can obtain the CNT 26 with $\mathrm{I}_{\mathrm{D}} / \mathrm{I}_{\mathrm{G}}<0.2$ which suggests the main products are SWCNTs. 
The literature has reported that the $\mathrm{I}_{\mathrm{D}} / \mathrm{I}_{\mathrm{G}}$ of SWCNT tends to remain under 0.2 and nearly constant as changing $\mathrm{E}_{\text {Laser }}$ [47]. In contrast, the $\mathrm{I}_{\mathrm{D}} / \mathrm{I}_{\mathrm{G}}$ of MWCNT decreases with increasing excitation energy [47]. From the data shown in Figure 8a-d, we can see that the $\mathrm{I}_{\mathrm{D}} / \mathrm{I}_{\mathrm{G}}$ ratio decreases rapidly with increasing catalyst temperature, but as the catalyst temperatures reach a threshold, the variations become smaller. Thus, we can distinguish the growing window for SWCNT and MWCNT by investigating the distribution of $\mathrm{I}_{\mathrm{D}} / \mathrm{I}_{\mathrm{G}}$ against the temperature and acetylene ratio.

In general, increasing the temperature and decreasing the gas ratio enhance the quality of CNT and, as the $\mathrm{I}_{\mathrm{D}} / \mathrm{I}_{\mathrm{G}}>0.2$, the quality degrades rapidly. In order to have a further understanding of the contributions of the temperature and of the acetylene ratio, the boundaries of the $\mathrm{I}_{\mathrm{D}} / \mathrm{I}_{\mathrm{G}}=0.2$ are outlined in the white lines in Figure $8 \mathrm{a}-\mathrm{d}$ with a corresponding linearly fitted black lines and its linear equations labelled in each panel. The corresponding slopes are used to assess the degree of the influence from the gas ratio on the CNT quality and the fabrication of SWCNT and MWCNT. The positive slopes depict that the increasing acetylene ratio decreases the CNT quality.

A steeper slope (Figure $8 \mathrm{~b}, 4.55{ }^{\circ} \mathrm{C} / \mathrm{Q}_{\mathrm{A} / \mathrm{H}} \%$ ) for HFR shows that increasing the impingement rate of carbon at catalyst results in a quality degradation. The LFR has a shallower slope (Figure $8 \mathrm{a}, 3.44{ }^{\circ} \mathrm{C} / \mathrm{Q}_{\mathrm{A} / \mathrm{H}} \%$ ), indicating that the quality does not degrade as the carbon impingement rate is increased. This is because the number of collision (total pressure) is higher at HFR than LFR. Interestingly, in Figure $8 \mathrm{c}$ and $\mathrm{d}$, the slopes are similar and it implies that growing conditions for s-SWCNT are similar, as can be observed in the following section. By comparing Figure 8a-d with Figure 9, the growth conditions above the black lines can have the higher RBM intensities which point to the higher production yields of SWCNT. Thus, the linearly fitted equations could serve as a guide for fabricating SWCNT, that can be type-selected, but more research is needed.

The temperature-intercepts at $\mathrm{Q}_{\mathrm{A} / \mathrm{H}}=2 \%$ in Figure 8a-d represent the lowest temperature for which $\mathrm{I}_{\mathrm{D}} / \mathrm{I}_{\mathrm{G}}=0.2$ and exceeding this temperature, the quality of CNT can be maintained without any significant variation. These temperature-intercepts are higher than the eutectoid temperature of $\gamma / \alpha-\mathrm{Fe}$, which is $740{ }^{\circ} \mathrm{C}$. It suggests that the metallic route is able to better the CNT quality, with smaller fluctuations than the carbide route. The best $\mathrm{I}_{\mathrm{D}} / \mathrm{I}_{\mathrm{G}}(0.06)$ is achieved at catalyst temperature of $850{ }^{\circ} \mathrm{C}$, comparable with thermal CVD (0.07) [48] and significantly better than PECVD (0.3) 
1 [49]. Moreover, the temperature which gives us the high quality, $850{ }^{\circ} \mathrm{C}$, is also consistent with Kimura et al. [39]. It should be mentioned that our substrate is at $490{ }^{\circ} \mathrm{C}$ which can be integrated with semiconductor manufacturing processes.

Generally, we find that the SWCNTs are mostly fabricated in the areas above the black lines defined in Figure 8 and above the corresponding y-intercepts lie the boundary temperatures for SWCNT growth. The higher process temperature and smaller acetylene ratio are still the important directions to improve the yield of SWCNTs. So, it is crucial to improve the heat management of the sample, such as afforded by the PTCVD system. Moreover, we can see that the LFR has higher production yields of SWCNT than the HFR.

\subsubsection{Selective growth of SWCNTs}

The RBM frequencies are measured using $\mathrm{E}_{\text {Laser }}=2.41$ (Figure 9a-d) and $1.58 \mathrm{eV}$ (Figure 9e,f). The $\mathrm{E}_{\text {Laser }}=2.41 \mathrm{eV}$, helps us to classify s-SWCNT and $\mathrm{m}-\mathrm{SWCNT}$ and $\mathrm{E}_{\text {Laser }}=1.58 \mathrm{eV}$ only probes the s-SWCNT [42]. The summed $\mathrm{I}_{\mathrm{RBM}}$ are plotted against the $\mathrm{T}_{\mathrm{C}}$ and $\mathrm{Q}_{\mathrm{A} / \mathrm{H}}$ in Figure $9 \mathrm{a}-\mathrm{f}$. The intensity of $\mathrm{RBM}$ is obtained from the Lorentzian fitting, as discussed above. What is interesting in Figure 9a-d is that the windows of growth temperature for m-SWCNT in either the LFR or HFR are larger than for s-SWCNT, and the RBM intensities of m-SWCNT are generally higher than the s-SWCNT across the parameter space investigated.

The most striking observation to emerge from the comparison of Figure $9 \mathrm{a}$ and $\mathrm{c}$ is associated with the conditions for preferential growth of s-SWCNT. We observe that the smaller acetylene ratio $\left(\mathrm{Q}_{\mathrm{A} / \mathrm{H}}<10 \%\right)$ favours the growth of s-SWCNT and the $\mathrm{Q}_{\mathrm{A} / \mathrm{H}}>10 \%$ is better for $\mathrm{m}-\mathrm{SWCNT}$ growth. Several studies have found the preferential growth via tuning of temperature, and growth time but the effect from reactant gas ratio on preferential growth has not been discussed [42, 47]. Thus, this finding points to the route for preferential growth of type-selective SWCNT, on substrates held at low temperature using the PTCVD process.

Interestingly, the HFR shows a weaker trend for preferential m-SWCNT growth compared with the LFR, but can still been observed that, for $\mathrm{Q}_{\mathrm{A} / \mathrm{H}}>10 \%$, the $\mathrm{m}-\mathrm{SWCNT}$ predominate. Conversely, the s-SWCNT is poorly synthesised, as shown in Figure $9 \mathrm{~b}$ and d. Especially for $\mathrm{Q}_{\mathrm{A} / \mathrm{H}}=16-18 \%$ between $\mathrm{T}_{\mathrm{S}}=430$ and $450{ }^{\circ} \mathrm{C}$ of the HFR which correspond to the $\mathrm{T}_{\mathrm{C}}=750$ and $800^{\circ} \mathrm{C}$, the yields of s-SWCNT are almost absent and only the m-SWCNTs are fabricated, as shown in Figure $9 \mathrm{~b}$ and d. From 
1 Figure $9 \mathrm{a}-\mathrm{d}$, by using the $\mathrm{E}_{\text {Laser }}=2.41 \mathrm{eV}$, we conclude that the yield of $\mathrm{m}-\mathrm{SWCNT}$ is 2 generally higher than the s-SWCNT and $\mathrm{Q}_{\mathrm{A} / \mathrm{H}}>10 \%$ is better for preferential growth 3 of m-SWCNT.

4 The more surprising results based on the RBM intensity measured by the

$5 \quad \mathrm{E}_{\text {Laser }}=1.58 \mathrm{eV}$ shows that the s-SWCNTs are grown in the whole range of acetylene

6 ratios and with a boarder temperature range when compared to Figure $9 \mathrm{a}$ and $\mathrm{b}$.

7 Figure $9 \mathrm{e}$ and $\mathrm{f}$ also suggest that the high temperature $\left(\mathrm{T}_{\mathrm{S}}>450{ }^{\circ} \mathrm{C}\right)$ can increase the

8 s-SWCNT yield and it is consistent with the results obtained by the $\mathrm{E}_{\text {Laser }}=2.41 \mathrm{eV}$

9 (Figure 9a-b). The difference is that the growth temperature and $\mathrm{E}_{\text {Laser }}=1.58 \mathrm{eV}$

10 reveals that s-SWCNT can be fabricated under $800{ }^{\circ} \mathrm{C}$ of catalyst temperature, which 11 corresponds to $450{ }^{\circ} \mathrm{C}$ at substrate.

12 In terms of the acetylene ratio, the HFR exhibits a more significant trend that the 13 yield of s-SWCNT decreases with increasing acetylene ratio, which is similar to the 14 case of the $\mathrm{E}_{\text {Laser }}=2.41 \mathrm{eV}$, as shown in Figure 9b. However, in the case of LFR, 15 Figure 9e shows that the s-SWCNT can be grown across the whole range of acetylene 16 ratio. Thus, the LFR provides a greater freedom in the use of acetylene ratio. In 17 conclusion, from Figure 9a-d, we recommend that the conditions for the preferential 18 growth of type-selective s-SWCNT are $\mathrm{Q}_{\mathrm{A} / \mathrm{H}}<10 \%$ and above $\mathrm{T}_{\mathrm{S}}=450{ }^{\circ} \mathrm{C}$ with 19 applying LFR. For only m-SWCNT, the preferential growth window is relatively 20 smaller with $\mathrm{Q}_{\mathrm{A} / \mathrm{H}}=16-18 \%$ and a temperature between $\mathrm{T}_{\mathrm{S}}=430$ and $450{ }^{\circ} \mathrm{C}$ under 21 HFR conditions. In addition, the high uniformity is confirmed by measuring 10 different positions across the sample (see Fig. SI1 in Supplementary Information). 

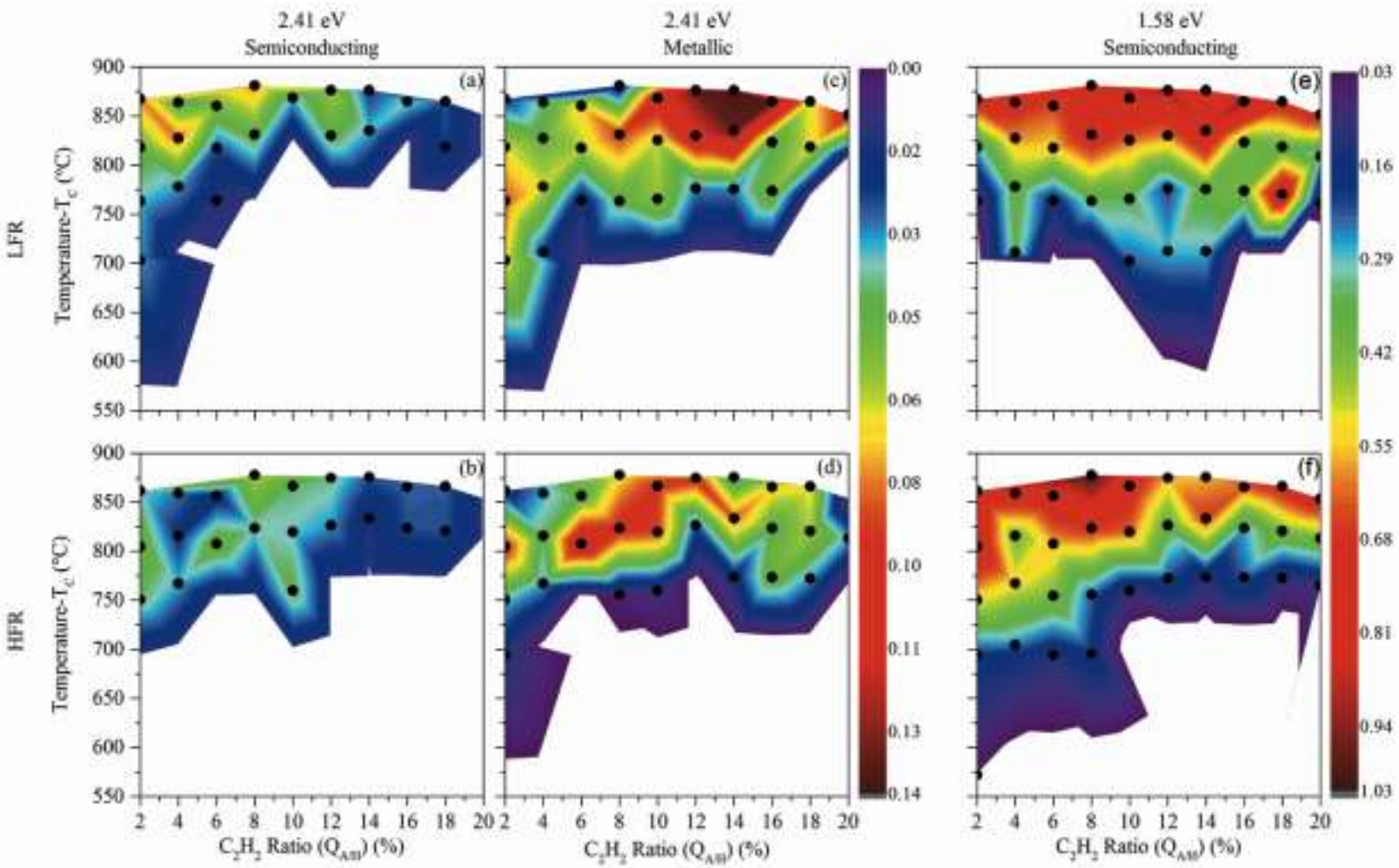

Figure 9. The distributions of the summed RBM intensity against the catalyst temperature and acetylene ratio. (a)-(d) The yields of semiconducting and metallic

4 SWCNT are represented by the summed RBM intensities measured by the $\mathrm{E}_{\text {Laser }}=2.41$ $\mathrm{eV}$ and are correlated with the catalyst temperature and acetylene to show the preferential growth windows for semiconducting and metallic SWCNT. (e)-(f) The summed $\mathrm{RBM}$ intensity measured by the $\mathrm{E}_{\text {Laser }}=1.58 \mathrm{eV}$ which only probes the semiconducting SWCNT. By using the $\mathrm{E}_{\text {Laser }}=1.58 \mathrm{eV}$, we found that the semiconducting SWCNTs are grown at low catalyst temperature and in the wide range of acetylene ratio. The blacks dots are the data points.

\section{Conclusions}

In summary, the best growth rate obtained here is $420 \mathrm{~nm} / \mathrm{s}$, without using plasma

14 and/or water, at a substrate temperature of $450{ }^{\circ} \mathrm{C}$. The lowest substrate temperature

$15\left(\mathrm{~T}_{\mathrm{S}}\right)$ at which we can obtain $\mathrm{CNT}$ is $320^{\circ} \mathrm{C}$. As the catalyst temperature nears the 16 eutectoid temperature of the catalyst metal and the carbon, the growth rate is likely to 17 be maximised. The major factor controlling CNT quality is the process temperature, 18 where the $\mathrm{I}_{\mathrm{D}} / \mathrm{I}_{\mathrm{G}}$ decreases with increasing the temperature. By comparing the RBM 19 intensities measured, preferential growth of s-SWCNT occurs at substrate 
1 temperatures above $450{ }^{\circ} \mathrm{C}$ and the acetylene ratio being smaller than $10 \%$. The

2 preferential growth of m-SWCNT occurs at substrate temperatures between $\mathrm{T}_{\mathrm{S}}=430$

3 and $450{ }^{\circ} \mathrm{C}$ and the acetylene ratios between 16 and $18 \%$.

4 A novel growth model for top-heating assisted CNT fabrication is proposed to 5 interpret the high growth rate of CNT obtained by PTCVD. In our model, the optical 6 heating induces a higher carbon diffusivity and carbon solubility at the top surface of 7 the catalyst, to lead to high growth rate with tip-growth mechanism. Moreover, the

8 chemical potential gradient through the catalyst generated by the difference between

9 the curvatures of the top and the bottom catalyst surfaces is the third force that 10 enhances the CNT growth.

11 Our results demonstrate that PT-CVD is the technique that can provide control over 12 the CNT growth, excellent quality and fast growth rates, whilst maintaining the 13 substrate at temperatures that are compatible with CMOS manufacturing processes. 14 The barrier between the technological requirement for high-quality, type-selected 15 CNTs and the requirement for maintaining substrates at low temperatures has now 16 been overcome.

17 
2 [1] Anguita JV, Cox DC, Ahmad M, Tan YY, Allam J, Silva SRP. Highly

3 transmissive carbon nanotube forests grown at low substrate temperature. Adv Funct

4 Mater. 2013;23(44):5502-9.

5 [2] Dabera GDMR, Jayawardena KDGI, Prabhath MRR, Yahya I, Tan YY, Nismy

6 NA, et al. Hybrid carbon nanotube networks as efficient hole extraction layers for

7 organic photovoltaics. ACS Nano. 2013;7(1):556-65.

8 [3] Derycke V, Martel R, Appenzeller J, Avouris P. Carbon nanotube inter- and 9 intramolecular logic gates. Nano Lett. 2001;1(9):453-6.

10 [4] Javey A, Guo J, Wang Q, Lundstrom M, Dai HJ. Ballistic carbon nanotube 11 field-effect transistors. Nature. 2003;424(6949):654-7.

12 [5] Jung Y, Li XK, Rajan NK, Tayor AD, Reed MA. Record high efficiency 13 single-walled carbon nanotube/silicon $\mathrm{p}-\mathrm{n}$ junction solar cells. Nano Lett. $14 \quad 2013 ; 13(1): 95-9$.

15 [6] Javey A, Kim H, Brink M, Wang Q, Ural A, Guo J, et al. High-kappa dielectrics 16 for advanced carbon-nanotube transistors and logic gates. Nat Mater. 17 2002;1(4):241-6.

18 [7] Wong HSP. Beyond the conventional transistor. IBM J Res Dev. 19 2002;46(2-3):133-68.

20 [8] Puretzky AA, Geohegan DB, Jesse S, Ivanov IN, Eres G. In situ measurements 21 and modeling of carbon nanotube array growth kinetics during chemical vapor 22 deposition. Appl Phys A-Mater. 2005;81(2):223-40.

23 [9] Vollebregt S, Ishihara R, Tichelaar FD, Hou Y, Beenakker CIM. Influence of the 24 growth temperature on the first and second-order Raman band ratios and widths of 25 carbon nanotubes and fibers. Carbon. 2012;50(10):3542-54.

26 [10] Patole SP, Alegaonkar PS, Lee HC, Yoo JB. Optimization of water assisted 27 chemical vapor deposition parameters for super growth of carbon nanotubes. Carbon. 28 2008;46(14):1987-93.

29 [11] Ahmad M, Anguita JV, Stolojan V, Carey JD, Silva SRP. Efficient coupling of 30 optical energy for rapid catalyzed nanomaterial growth: High-quality carbon nanotube 31 synthesis at low substrate temperatures. ACS Appl Mater Inter. 2013;5(9):3861-6. 
1 [12] Chen GY, Jensen B, Stolojan V, Silva SRP. Growth of carbon nanotubes at 2 temperatures compatible with integrated circuit technologies. Carbon. 3 2011;49(1):280-5.

4 [13] Shang NG, Tan YY, Stolojan V, Papakonstantinou P, Silva SRP. High-rate 5 low-temperature growth of vertically aligned carbon nanotubes. Nanotechnology. $6 \quad 2010 ; 21(50): 505604$.

7 [14] Zhang C, Yan F, Allen CS, Bayer BC, Hofmann S, Hickey BJ, et al. Growth of 8 vertically-aligned carbon nanotube forests on conductive cobalt disilicide support. $\mathrm{J}$ 9 Appl Phys. 2010;108(2).

10 [15] Ehrenreich H, Philipp HR, Segall B. Optical properties of aluminum. Phys Rev. 11 1963;132(5):1918-28.

12 [16] Harris L, Piper J. Transmittance and reflectance of aluminum-oxide films in far 13 infrared. J Opt Soc Am. 1962;52(2):223-4.

14 [17] Khachadorian S, Scheel H, Cantoro M, Colli A, Ferrari AC, Thomsen C. The 15 morphology of silicon nanowire samples: A Raman study. Phys Status Solidi B. 16 2009;246(11-12):2809-12.

17 [18] Baker RTK, Harris PS, Thomas RB, Waite RJ. Formation of filamentous carbon 18 from iron, cobalt and chromium catalyzed decomposition of acetylene. J Catal. $19 \quad 1973 ; 30(1): 86-95$.

20 [19] Boskovic BO, Stolojan V, Khan RUA, Haq S, Silva SRP. Large-area synthesis 21 of carbon nanofibres at room temperature. Nat Mater. 2002;1(3):165-8.

22 [20] Schneider A, Inden G. Carbon diffusion in cementite $(\mathrm{Fe}(3) \mathrm{C})$ and Hagg carbide $23(\mathrm{Fe}(5) \mathrm{C}(2))$. Calphad. 2007;31(1):141-7.

24 [21] Helveg S, Lopez-Cartes C, Sehested J, Hansen PL, Clausen BS, Rostrup-Nielsen $25 \mathrm{JR}$, et al. Atomic-scale imaging of carbon nanofibre growth. Nature. 26 2004;427(6973):426-9.

27 [22] Hofmann S, Csanyi G, Ferrari AC, Payne MC, Robertson J. Surface diffusion: 28 The low activation energy path for nanotube growth. Phys Rev Lett. 29 2005;95(3):036101.

30 [23] Moseler M, Cervantes-Sodi F, Hofmann S, Csanyi G, Ferrari AC. Dynamic 31 catalyst restructuring during carbon nanotube growth. ACS Nano. 32 2010;4(12):7587-95. 
1 [24] Fazle Kibria AKM, Mo YH, Nahma KS, Kim MJ. Synthesis of narrow-diameter

2 carbon nanotubes from acetylene decomposition over an iron-nickel catalyst

3 supported on alumina. Carbon. 2002;40(8):1241-7.

4 [25] Navarro López P, Rodríguez Ramos I, Guerrero Ruiz A. A study of carbon

5 nanotube formation by $\mathrm{C} 2 \mathrm{H} 2$ decomposition on an iron based catalyst using a pulsed

6 method. Carbon. 2003;41(13):2509-17.

7 [26] Kirchner A, Kieback B. Solubility of Carbon in Nanocrystalline a -Iron. J 8 Nanomater. 2012;2012:1-4.

9 [27] Klinke C, Bonard JM, Kern K. Thermodynamic calculations on the catalytic 10 growth of multiwall carbon nanotubes. Phys Rev B. 2005;71(3):035403.

11 [28] Bonnet F, Ropital F, Berthier Y, Marcus P. Filamentous carbon formation caused 12 by catalytic metal particles from iron oxide. Mater Corros. 2003;54(11):870-80.

13 [29] Youn SK, Frouzakis CE, Gopi BP, Robertson J, Teo KBK, Park HG. 14 Temperature gradient chemical vapor deposition of vertically aligned carbon 15 nanotubes. Carbon. 2013;54:343-52.

16 [30] Cantoro M, Hofmann S, Pisana S, Scardaci V, Parvez A, Ducati C, et al. 17 Catalytic chemical vapor deposition of single-wall carbon nanotubes at low 18 temperatures. Nano Lett. 2006;6(6):1107-12.

19 [31] Chhowalla M, Teo KBK, Ducati C, Rupesinghe NL, Amaratunga GAJ, Ferrari 20 AC, et al. Growth process conditions of vertically aligned carbon nanotubes using 21 plasma enhanced chemical vapor deposition. J Appl Phys. 2001;90(10):5308-17.

22 [32] Jönsson M, Nerushev OA, Campbell EEB. In situ growth rate measurements 23 during plasma-enhanced chemical vapour deposition of vertically aligned multiwall 24 carbon nanotube films. Nanotechnology. 2007;18(30):305702.

25 [33] Kishimoto S, Kojima Y, Ohno Y, Sugai T, Shinohara H, Mizutani T. Growth of 26 mm-long carbon nanotubes by grid-inserted plasma-enhanced chemical vapor 27 deposition. Jpn J Appl Phys. 2005;44(4A):1554-7.

28 [34] Morjan RE, Maltsev V, Nerushev O, Yao Y, Falk LKL, Campbell EEB. High 29 growth rates and wall decoration of carbon nanotubes grown by plasma-enhanced 30 chemical vapour deposition. Chem Phys Lett. 2004;383(3-4):385-90.

31 [35] Zhong GF, Iwasaki T, Robertson J, Kawarada H. Growth kinetics of $0.5 \mathrm{~cm}$ 32 vertically aligned single-walled carbon nanotubes. J Phys Chem B. $332007 ; 111(8): 1907-10$. 
1 [36] Hata K, Futaba DN, Mizuno K, Namai T, Yumura M, Iijima S. Water-assisted

2 highly efficient synthesis of impurity-free single-walled carbon nanotubes. Science.

3 2005;306:1362-4.

4 [37] Sugime H, Noda S. Millimeter-tall single-walled carbon nanotube forests grown

5 from ethanol. Carbon. 2010;48(8):2203-11.

6 [38] Wirth CT, Bayer BC, Gamalski AD, Esconjauregui S, Weatherup RS, Ducati C,

7 et al. The Phase of Iron Catalyst Nanoparticles during Carbon Nanotube Growth.

8 Chem Mater. 2012;24(24):4633-40.

9 [39] Kimura H, Futaba DN, Yumura M, Hata K. Mutual exclusivity in the synthesis

10 of high crystallinity and high yield single-walled carbon nanotubes. J Am Chem Soc.

11 2012;134(22):9219-24.

12 [40] Kataura H, Kumazawa Y, Maniwa Y, Umezu I, Suzuki S, Ohtsuka Y, et al. 13 Optical properties of single-wall carbon nanotubes. Synthetic Met. 14 1999;103(1-3):2555-8.

15 [41] Lee HW, Yoon Y, Park S, Oh JH, Hong S, Liyanage LS, et al. Selective 16 dispersion of high purity semiconducting single-walled carbon nanotubes with 17 regioregular poly(3-alkylthiophene)s. Nat Commun. 2011;2:541.

18 [42] Qu LT, Du F, Dai LM. Preferential syntheses of semiconducting vertically 19 aligned single-walled carbon nanotubes for direct use in FETs. Nano Lett. 20 2008;8(9):2682-7.

21 [43] Dresselhaus MS, Dresselhaus G, Saito R, Jorio A. Raman spectroscopy of 22 carbon nanotubes. Phys Rep. 2005;409(2):47-99.

23 [44] Thomsen C, Reich S. Double resonant raman scattering in graphite. Phys Rev 24 Lett. 2000;85(24):5214-7.

25 [45] Kalbac M, Hsieh YP, Farhat H, Kavan L, Hofmann M, Kong J, et al. Defects in 26 individual semiconducting Single wall carbon nanotubes: Raman spectroscopic and in 27 situ raman spectroelectrochemical study. Nano Lett. 2010;10(11):4619-26.

28 [46] Ferrari AC, Meyer JC, Scardaci V, Casiraghi C, Lazzeri M, Mauri F, et al. 29 Raman spectrum of graphene and graphene layers. Phys Rev Lett. 30 2006;97(18):187401.

31 [47] Ouyang Y, Cong LM, Chen L, Liu QX, Fang Y. Raman study on single-walled 32 carbon nanotubes and multi-walled carbon nanotubes with different laser excitation 33 energies. Physica E. 2008;40(7):2386-9. 
1 [48] Qingwen L, Hao Y, Yan C, Jin Z, Zhongfan L. A scalable CVD synthesis of 2 high-purity single-walled carbon nanotubes with porous $\mathrm{MgO}$ as support material. $\mathrm{J}$ 3 Mater Chem. 2002;12(4):1179-83.

4 [49] Maschmann MR, Amama PB, Goyal A, Iqbal Z, Gat R, Fisher TS. Parametric 5 study of synthesis conditions in plasma-enhanced CVD of high-quality single-walled 6 carbon nanotubes. Carbon. 2006;44(1):10-8.

7 